\title{
VISCOSITY METHOD IN ROBOTIC MILKING SYSTEM FOR DETECTION OF SOMATIC CELL COUNT IN MILK
}

\author{
Ivars Lusis, Armins Laurs, Vita Antane \\ Latvia University of Life Sciences and Technologies, Latvia \\ ivars.lusis@1lu.lv, armins.laurs@promedia.lv,vita.antane@1lu.lv
}

\begin{abstract}
The objective of this study was to evaluate performance of automated measurement of whole milk somatic cell count (SCC) by the viscosity method. Gel viscosity of mixture from a small portion of whole milk and SCC indicator reagent was assumed to be related to the number of somatic cells in milk. The principle of detection was based on the length of the time necessary for the magnet to pass through the mixture. One farm with a milking robot equipped with an in-built processor for viscosity detection and permanent use was selected. Viscosity SCC data of 111 dairy cows were obtained from the management system of the milking robot for 4 consecutive days around the milk recording test-day. Whole milk samples from all cows were sent to the accredited dairy laboratory for detection of SCC by the fluoro-opto-electronic method (reference method). To characterize the performance of automated measurement of the viscosity method used to detect cows with high SCC (more than 200000 cells $\cdot \mathrm{ml}^{-1}$ ), measured by the reference method, the Cohen's kappa for all milking sessions was calculated. Qualitative agreement of SCC measurement by the viscosity method for the values below 100000 or above 500000 cells $\cdot \mathrm{ml}^{-1}$ shows a reliable result already at one separate milking, whereas for the values between 100000 and 500000 cells $\cdot \mathrm{ml}^{-1}$ an affirmation that SCC is more than $200000 \mathrm{cells} \cdot \mathrm{ml}^{-1} \mathrm{can}$ be based on a calculated mean over 3 to 5 consecutive milkings (kappa $=0.81 \pm 0.09$ ). Quantitative agreement of the SCC results of the viscosity method is only moderate when compared to the laboratory method results. Viscosity method in robotic milking system for detection of milk somatic cell count as a possible tool for the evaluation of the cow udder health status is objective, informative, and has relatively low costs.
\end{abstract}

Keywords: milk, cells, udder, bovine, robot.

\section{Introduction}

Milk with a high somatic cell count indicates a cow with udder health problems which can be clinical or subclinical. Detection of alerts for clinical mastitis are based on gross alterations in milk, presence of clots, milk colour or temperature changes registered by appropriate sensors in the milking system or milking robot [1]. For detection of subclinical mastitis the test-day SCC (somatic cell count) is the most common indicator for surveillance in dairy industries worldwide [2]. In general, SCC data at a cow level are available from milk recording test days only once per month. To increase the reliability of the test-day SCC and to be able accurately detect subclinical mastitis more frequent data collection is necessary [2;3]. Many authors agree that producers should not rely only on the single testday SCC results, when managing mastitis, due to the milking-to-milking variations [4]. Some milking robots are equipped with sensors to estimate SCC for management and benchmarking purposes at every milking of cows [5]. Only subclinical mastitis alerts will be addressed further in this paper.

Measurement of the count of somatic cells in milk can be performed directly or indirectly. Direct methods by counting the cells as particles of due to precision are mostly applied at milk laboratories and widely accepted for reference purposes. However, over decades they are adapted for use on farms as portative devices, or installed in the milking system for routine use to find cows with high SCC [3].Indirect methods to detect high SCC are based on viscous gel formation from the mixture obtained from a portion of milk and specific reagent. Gel viscosity can be assessed visually, e.g. the California Mastitis Test (CMT) is widely used in dairy practice, mostly for very inaccurate measurement of SCC at the udder quarter level. More accurate an in automated way assessment of gel viscosity is read by sensors, e.g. the MQC-C2 sensor (milk quality control-cell count 2), which is based on a modified California mastitis test reaction and introduced together with the Lely A4 milking robot [6]. The MQC-C2 sensor measures SCC at cow level and is operated using the following five steps [6]: (1) a certain amount of milk is mixed with a certain amount of reagent, (2) the reagent reacts with the somatic cells in milk and changes the viscosity of the mixture, (3) a magnet is dropped through the mixed substance, (4) the viscosity is determined by the time taken it travels through the mixture, (5) the related somatic cell count is calculated by software. It should be mentioned that currently the sensors are so high in precision that transform to the quantitative outcome, i.e. the number of somatic cells per one millilitre of milk at every milking time. However, there is limited information about online SCC detection by the viscosity method in milking robots. Mollenhorst et al. [7] published a 
research on somatic cell count assessment by the viscosity method, but used another sensor (MQC-C sensor installed at the milking robot Lely Astronaut A3) and concluded that the quarter level SCC assessment was superior to the cow level assessment. More recently, Fadul-Pacheco et al. [5] have done wide scale research on accuracy of measurements of the milk components (fat, protein, lactose) and SCC by the viscosity method as compared to the laboratory results on ten dairy farms with automatic milking systems Lely Astronaut A4 and the sensors MQC-C2. In their conclusions the researchers clearly indicate that it will be necessary to establish validation procedures and thresholds according to the different possible data usages (e.g., farm management, benchmarking and genetic evaluations).For the udder health purpose using the cow-level data, a threshold of 200000 somatic cells per ml of milk could be used to split the cow population in groups with little and high probability of subclinical mastitis [8;9]. Therefore, it is necessary to clarify agreement and the degree of closeness of the SCC results by the viscosity method and reference method in relation to this threshold.

The aim of this study was to characterise and compare measurements of somatic cell count by the MQC-C2 sensor, which works based on the principle of viscosity method, for qualitative and quantitative agreement with the data obtained in the laboratory for individual cows.

\section{Materials and methods}

One farm with two milking robots equipped with a built-inMQC-C2 sensors for SCC detection in milk was selected. Viscosity SCC data of 111 dairy cows were obtained from the management system of the milking robot for four consecutive days around the milk recording test day. Whole milk samples from all cows were taken on the test day and sent to the accredited dairy laboratory for detection of SCC by the fluoro-opto-electronic method (reference method). All SCC data were converted into linear scores $\left(L S_{s c c}\right)$ by the formula (1) before statistical comparison.

$$
L S_{S C C}=\log _{2}\left(S C C \times 10^{-5}\right)+3 .
$$

To characterize the performance of automated measurement of the viscosity method used to detect cows with high SCC (more than 200000 cells per ml), measured by the reference method, the Cohen's kappa from all milking sessions was calculated, and the agreement was evaluated. The number of false positives and false negatives to detect cows with high SCC were also calculated. To characterize the quantitative closeness of the SCC results by the viscosity method and by the reference method, the Lin's concordance coefficient from all milking sessions was calculated, and the agreement was evaluated [9]. Statistical analyses were performed by software STATA 12 and with extensions for method agreement calculations created by Steichen T.J. and Cox N.J. [9].

\section{Results and discussion}

Somatic cell count results by the viscosity method were obtained for all cows in milk $(n=120)$. For the current research, data were downloaded from the results of two milking robot units equipped with the MQC-C2 sensor and stored in the herd management system. Nine cows with less than 7 days in milk were excluded from the dataset because they had only SCC results measured by the viscosity sensor, but without the reference SCC measurements. Finally, the cows $(n=111)$ with two milking sessions before and five sessions after the test milking were left in the analysed dataset. The number of milking sessions for each cow varied between 5 and 21 times during the 4-day period. Therefore, the average number of milking in the 24-hour period was $2.86 \pm 0.07$ per cow.

Fig. 1 shows the somatic cell count determined by the viscosity method and reference method in 111 dairy cows at the given test milking. As generally accepted in veterinary practice and research done on the cow-level data, a threshold of 200000 somatic cells per ml of milk could be used to split the cow population in groups with little and high probability of subclinical mastitis [6-8]. Drawing both threshold lines on the scatter graph, four quadrants (Q1-Q4) are formed. Points at Q1 and Q4 represent discrepancy in SCC measured by the viscosity method and fluoro-opto-electronic method (reference method), in our data they are filled with several points, representing 2 overestimated cows (1.8\%) in Q1, and 11 underestimated cows (10\%) in Q4 with respect to the SCC threshold.Q2 and Q3 represent congruence of SCCby both methods. However, looking at the graph in Q3 all cows with the values less than 100000 cells per ml by the viscosity method are correctly classified as cows with the result by the reference method below the threshold 200000 somatic cells per ml. 
Also, high SCC cows over 500000 cells per ml in Q2 shows equivalence of both methods. Thus, in our data all points contributing to lowering of agreement among SCC qualitative assessment by both methods were placed in the middle range from 100000 to 500000 cells per ml. Thus, when the viscosity method is applied in practice, every cow with SCC level detected in this value range should be carefully interpreted, and the measurement of SCC continued and evaluated again at the next milking.

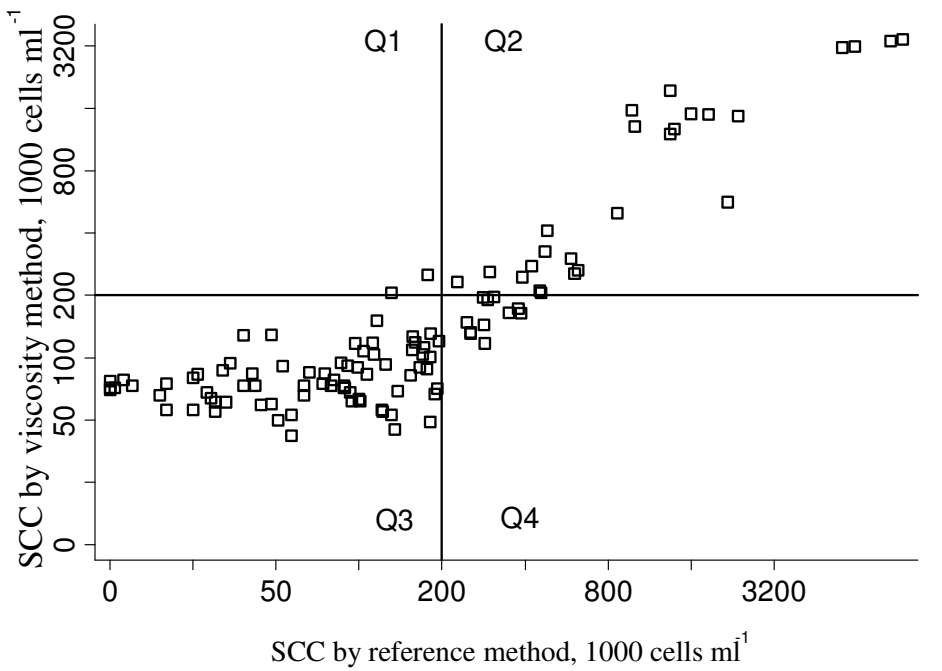

Fig. 1. Direct comparison of SCC results by viscosity method and reference method for two milking robot units each of them equipped with MQC-C2 sensor

Further analysis of agreement between the viscosity method and reference method, if the SCC results from both are expressed in qualitative sense, is carried out by expanding of the time window. In Table 1 other milkings in close proximity to the test milking for the same cows are included to allow additional comparisons. Due to milking-to-milking fluctuations of the SCC level in milk for the same cow, it is possible to observe a change of the current udder health status. It should be emphasised that this is not anymore a pure agreement of tests, but also the biological variability of SCC. Probably, also the SCC result obtained during the current test milking could be shifted on the other side of the SCC threshold just for one or a couple of milkings. The prevalence of cows with SCC above 200000 cells per $\mathrm{ml}$ was lower when measured by the viscosity method, because the count of false negative cows was higher than the count of false positive ones in all milkings. In general, the value of the Cohen's kappa $0.71 \pm 0.09$ for the given test milking showed substantial level of agreement. Milkings before and after the test milking showed no significant changein the degree of agreement. However, the mean values from several consecutive milkings showed considerable gain in agreement, and the Cohen's kappa values exceeded 0.80, suggesting almost perfect agreement according to well-known judgement of the extent of agreement [10]. Although, the highest kappa value $0.88 \pm 0.09$ was observed for the mean calculated from two SCC measurements by the viscosity method, namely, the test milking (0) and next milking time (+1), more consistent mean value can be seen from 3 or 5 consecutive milkings (Table 1). Therefore, it can be concluded that to detect cows with SCC more than 200000 cells per ml the viscosity method should be used on regular bases and not as only one observation. It should be mentioned that regular measurements by the viscosity method represent relatively low costs.

The expenses for the liquid reagent used for SCC measurements by the viscosity method can be summarized; during a month period 1 litre (costs 12 EUR in Latvia) per a robot group of 60 cows is necessary, if the measurement is undertaken at each milking of each cow.

Further analysis of the datawas carried out towards characterisation of the degree of closeness of the SCC results obtained by the viscosity method and reference method. If SCC by the reference method was below 50000 cells per ml, the results by the viscosity method were always too high (Fig. 1). Perhaps, there was some difficulty for the viscosity sensor to measure SCC low values. However, from the practical point of view, for purposes of the udder health assessment this is not critical. 
To calculate the upper and lower limits of agreement for the SCC results obtained by the viscosity method only the cows with SCC above 50000 cells per ml were left in the dataset $(n=85)$. In Fig. 2 we can see that the points are evenly scattered above and below the horizontal zero line corresponding to no difference.

Table 1

Overall agreement and Cohen's kappa coefficient of viscosity method for qualitative diagnostics at threshold of 200000 cells $\cdot \mathrm{ml}^{-1}$

\begin{tabular}{|c|c|c|c|c|c|c|c|c|}
\hline $\begin{array}{l}\text { Number } \\
\text { of cows, } n\end{array}$ & $\begin{array}{r}\text { Prevaler } \\
\text { with so } \\
\text { count } n \\
200000 \\
\end{array}$ & $\begin{array}{l}\text { of cows } \\
\text { atic cell } \\
\text { re than } \\
\text { ells } \cdot \mathbf{m l}^{-1}\end{array}$ & \begin{tabular}{|c|} 
Milkings by \\
order relative \\
to test ilking or
\end{tabular} & $\begin{array}{c}\text { False } \\
(+)\end{array}$ & $\begin{array}{c}\text { False } \\
(-)\end{array}$ & $\begin{array}{c}\text { Overall } \\
\text { agreement, } \\
\%\end{array}$ & $\begin{array}{c}\text { Cohen's } \\
\text { kappa } \\
\text { coefficient }\end{array}$ & $\begin{array}{c}\text { Standard } \\
\text { error of } \\
\text { kappa }\end{array}$ \\
\hline - & $\begin{array}{c}\text { by } \\
\text { reference } \\
\text { method }\end{array}$ & $\begin{array}{c}\text { by } \\
\text { viscosity } \\
\text { method }\end{array}$ & $\begin{array}{l}\text { Mean of two, } \\
\text { three and five } \\
\text { milkings }\end{array}$ & - & - & - & - & - \\
\hline 111 & $32 \%$ & $24 \%$ & -2 & 3 & 12 & $87 \%$ & 0.67 & 0.09 \\
\hline 110 & $32 \%$ & $25 \%$ & -1 & 3 & 11 & $87 \%$ & 0.69 & 0.09 \\
\hline 111 & $32 \%$ & $24 \%$ & 0 (test milking) & 2 & 11 & $88 \%$ & 0.71 & 0.09 \\
\hline 111 & $32 \%$ & $23 \%$ & +1 & 1 & 12 & $88 \%$ & 0.71 & 0.09 \\
\hline 110 & $32 \%$ & $21 \%$ & +2 & 0 & 13 & $88 \%$ & 0.70 & 0.09 \\
\hline 110 & $33 \%$ & $24 \%$ & +3 & 3 & 13 & $85 \%$ & 0.64 & 0.09 \\
\hline 107 & $31 \%$ & $22 \%$ & +4 & 2 & 12 & $87 \%$ & 0.67 & 0.09 \\
\hline 93 & $31 \%$ & $24 \%$ & +5 & 2 & 9 & $88 \%$ & 0.70 & 0.10 \\
\hline 111 & $32 \%$ & $33 \%$ & $\begin{array}{c}\text { Mean of } \\
-1 / 0\end{array}$ & 5 & 4 & $92 \%$ & 0.82 & 0.09 \\
\hline 111 & $32 \%$ & $32 \%$ & $\begin{array}{c}\text { Mean of } \\
0 /+1\end{array}$ & 3 & 3 & $95 \%$ & 0.88 & 0.09 \\
\hline 111 & $32 \%$ & $32 \%$ & $\begin{array}{c}\text { Mean of } \\
-1 / 0 /+1\end{array}$ & 4 & 5 & $92 \%$ & 0.81 & 0.09 \\
\hline 111 & $32 \%$ & $32 \%$ & $\begin{array}{c}\text { Mean of } \\
-2 /-1 / 0 \\
/+1 /+2\end{array}$ & 5 & 4 & $92 \%$ & 0.81 & 0.09 \\
\hline
\end{tabular}

Furthermore, the scatter of the points is random with no funnel effect, indicating that the size of discrepancy between the both methods of counting is not related to the diapason of the SCC. SCC measured values differ in $90 \%$ of cows up to two times or up to one unit in $\log _{2}$ scale. For example, if a cow has SCC measured by the viscosity method 200000 cells $\cdot \mathrm{ml}^{-1}$, it could be higher or lower in fact, but the producer has sufficient reliability that the herd bulk tank SCC will be ensured $\leq 400000$ cells $\cdot \mathrm{ml}^{-1}$ [11].However, it should be mentioned that $10 \%$ of cows showed even greater discrepancy (points in Fig. 2. above the upper and points below the lower limit of agreement).

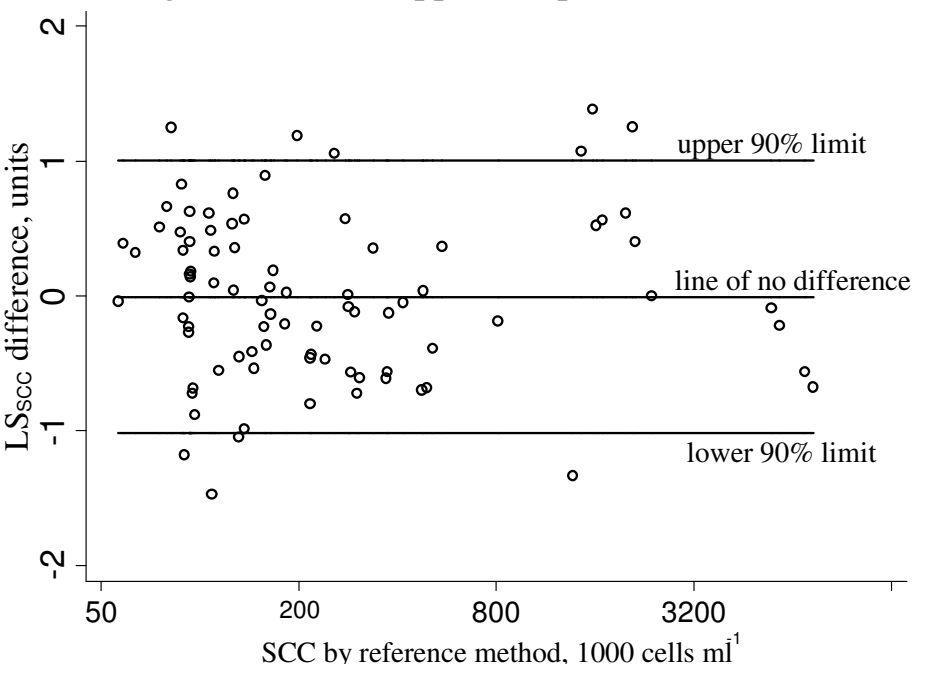

Fig. 2. Bland and Altman diagram showing upper and lower limits of agreement for SCC results obtained by viscosity method, if SCC by reference method was above 50000 cells $\cdot \mathrm{ml}^{-1}$ 
Also the Lin`s concordance correlation coefficient value of 0.94 at the test milking (Fig. 3) confirmed only moderate quantitative agreement of both methods. Milkings before and after the test milking showed even lower degree of agreement. Unlike the qualitative assessment shown in Table 1, the concordance correlation coefficient was not higher for the mean values of SCC over 3milkings $(-1 / 0 /+1)$ than the value at only one milking (Fig. 3).

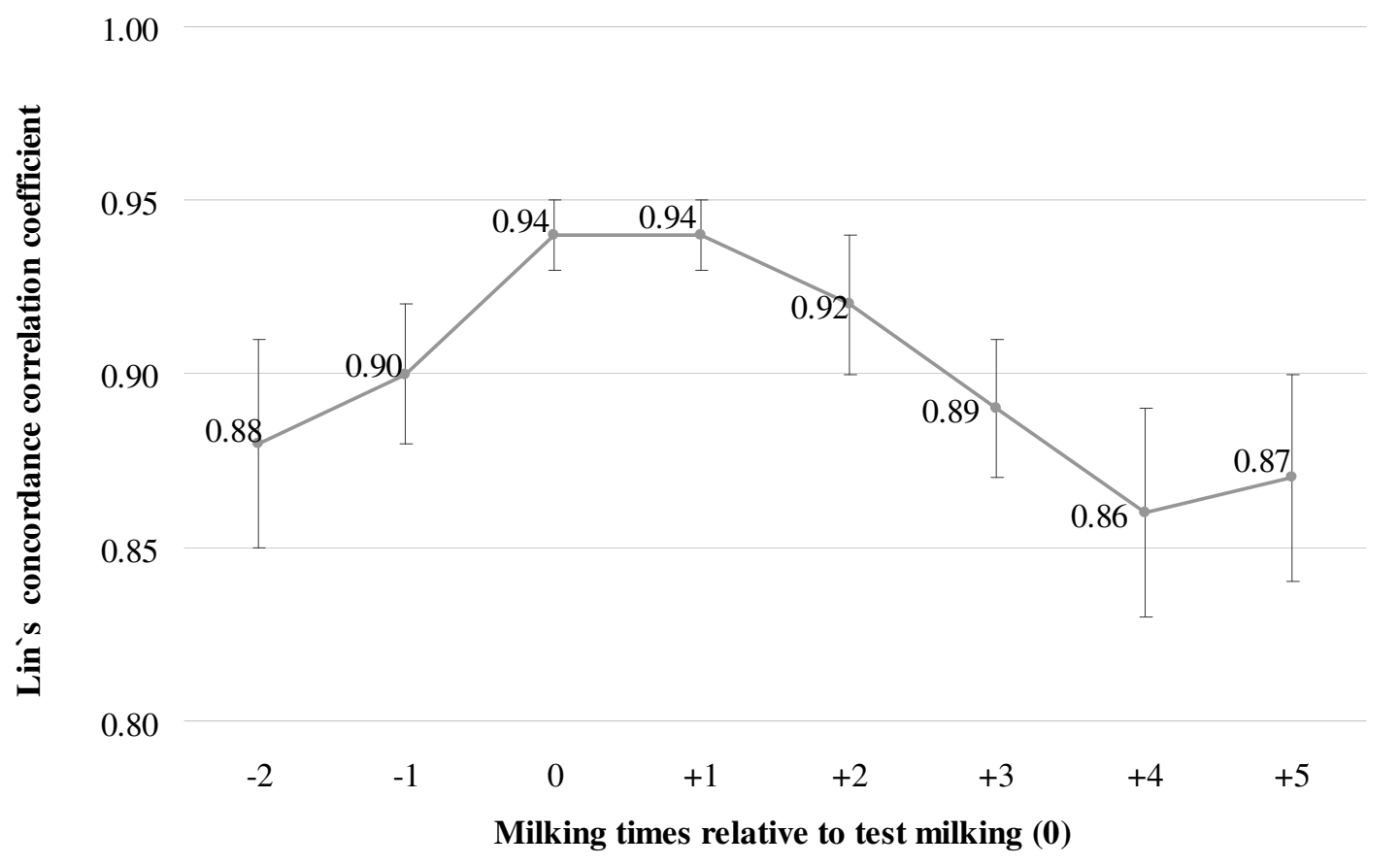

Fig. 3. Lin's concordance correlation coefficient at test milking ( $(0)$ and consecutive milkings before or after test milking

\section{Conclusions}

1. Somatic cell count (SCC) in milk measured by the viscosity method in the robotic milking system for evaluation of the cow udder health status is objective and informative, if specific SCC thresholds have been considered.

2. Qualitative agreement of SCC measurement by the viscosity method for the values below 100000 or above 500000 cells $\cdot \mathrm{ml}-1$ shows a reliable result already at one separate milking, whereas for the values between 100000 and 500000 cells.ml-1 affirmation that SCC is more than 200000 cells $\cdot \mathrm{ml}-1$ can be based on the calculated mean over 3 to 5 consecutive milkings.

3. Quantitative agreement of the SCC results by the viscosity method is only moderate for both the value of only one milking and the mean over three consecutive milkings compared to the laboratory method results.

4. Due to its relatively low costs, the viscosity method is suitable for use at each milking of each cow, which allows to calculate the mean SCC values when necessary.

\section{Acknowledgements}

We kindly express our thanks to the LELY Center Riga (SIA Pro Ceva) head IngemarsButkevics and the Farm Management Support team specialist SolvitaPetrauska, as well as to the owners of the dairy farm at SIA "Ritnieki" for the kind help with collecting data from the herd management system.

\section{References}

[1] Kamphuis C., Dela Rue B., Mein G., Jago J. Development of protocols to evaluate in-line mastitis-detection systems. Journal of Dairy Science, vol. 96, 2013, pp. 4047-4058.

[2] Ebrahimie E., Ebrahimi F., Ebrahimi M., Tomlinson S., Petrovski K.R. Hierarchical pattern recognition in milking parameters predicts mastitis prevalence. Computers and Electronics in Agriculture, vol. 147, 2018, pp. 6-11. 
[3] Lusis I., Antane V., Laurs A. Effectiveness of somatic cell count determination in the milking robots. Proceedings of International Scientific Conference "Engineering for Rural Development", May 27-28, 2010, Jelgava, Latvia, pp. 112-116.

[4] Quist M.A., LeBlanc S.J., Hand K.J., Lazenby D., Kelton D.F., Miglior F. Milking-to-milking variability for milk yield, fat and protein percentage, and somatic cell count. Journal of Dairy Science, vol. 91(9), 2008, pp. 3412-3423.

[5] Fadul-Pacheco, L., Lacroix, R., Vasseur, E., \& Lefebvre, D. M. Characterization of milk composition and somatic cell count estimates from automatic milking systems sensors. In: ICAR Technical Series Nr.23, 2018, pp. 53-63.

[6] Lely Dairy Equipment. [online] [10.03.2019]. Available at: http://www.lely.com/uploads/original/documents/Brochures/Dairy/Dairy_equipment_brochure_2 014

[7] Mollenhorst H., Tol P.P.J., Hogeveen H. Somatic cell count assessment at the quarter or cow milking level. Journal of Dairy Science, vol. 93, 2010, pp. 3358-3364.

[8] Goncalves J.L., Kamphuis C., Martins C.M.M.R., Barreiro J.R., Tomazi T., Gameiro A.H., dos Santos M.V. Bovine subclinical mastitis reduces milk yield and economic return. Livestock Science, vol. 210, 2018, pp. 25-32.

[9] Steichen, T. J., Cox N. J. A Note on the Concordance Correlation Coefficient. The Stata Journal: Promoting Communications on Statistics and Stata, Vol. 2(2), 2002, pp. 183-189.

[10] Watson P. F., Petrie A. Method agreement analysis: A review of correct methodology. Theriogenology, vol. 73(9), 2010. pp. 1167-1179.

[11] Regulation (EC) No853/2004 of the European Parliament and of the Council of 29 April 2004 laying down specific hygiene rules for on the hygiene of foodstuffs. "Annex III: Specific requirements, Section IX: Raw milk and dairy products" Available at: https://eurlex.europa.eu/legal-content/EN/TXT/PDF/?uri = CELEX:32004R0853\&from = LV 